\title{
Dispersão de Poluentes na Camada Limite Atmosférica Turbulenta: Fechamento Fickiano Modificado e a Presença de Fase
}

\author{
Debora Lidia Gisch \\ Bardo Ernst Josef Bodmann \\ Marco Túllio Menna Barreto de Vilhena \\ Universidade Federal do Rio Grande do Sul - Programa de Pós-Graduação Engenharia Mecânica, \\ 90050-170, Rua Sarmento Leite, 425 - $2^{\circ}$ Andar, Porto Alegre, RS \\ E-mail: debora.gisch@ufrgs.br, bardo.bodmann@ufrgs.br, vilhena@mat.ufrgs.br
}

\begin{abstract}
RESUMO
A dispersão de poluentes é um fenômeno complexo dado que ao observar um chaminé pode-se identificar diversas estruturas como vórtices e turbilhões, flutuações na densidade do poluente e na velocidade da dispersão. Um reflexo dessa complexidade é que, para reproduzi-la, há modelos que utilizam um grande número de parâmetros. Neste trabalho constrói-se um modelo de dispersão de poluentes que apresenta estas estruturas apenas introduzindo um coeficiente de difusão complexo, modificando, assim, o fechamento Fickiano.

A Camada Limite Planetária (CLP) é o domínio de interesse da grande maioria dos modelos de dispersão de poluentes, já que nela os fenômenos turbulentos são presentes contribuindo para a dispersão de poluentes. A proximidade (CLP) à superfície terrestre geram forçantes mecânicas e térmicas que são responsáveis pelas características turbulentas como vórtices e turbilhões que vão da ordem $10^{-3}$ a $10^{3}$ metros [1]. Esses vórtices e turbilhões podem ser representados através de Estruturas Coerentes (ECs) e essas estruturas são dominadas por uma fase. A definição (ECs) não é única, mas para este trabalhos usamos a definição formal de coerência, [2] e [3].

O modelo analítico de dispersão de poluentes mais estudado é o que tem por base a equação advecçãodifusão [4] onde diversas simplificações como aplicações das médias de Reynolds e o fechamento Fickiano são aplicados para que a solução seja alcançada mais facilmente. Essas simplificações tornam o modelo determinístico e linear, mesmo o fenômeno sendo estocástico e não linear.

Para resgatar algumas características do fenômeno turbulento neste trabalho sugeriu-se a inclusão de uma fase na equação advecção-difusão tridimensional e transiente, já que (ECs) são características turbulentas dominadas pela fase. Assim resolve-se a equação advecção-difusão e ao obter-se a solução inclui-se uma modificação no fechamento Fickiano, através da substituição do coeficiente de difusão por um coeficiente de difusão complexo e formando a grandeza que representa a distribuição de poluentes de forma bilinear [5]. Esse coeficiente complexo torna a solução da equação advecção-difusão complexa, ou seja a solução está no corpo dos complexos com módulo e fase. A distribuição da concentração deve ser real e semi-positiva, portanto usa-se uma analogia aos fenômenos eletromagnéticos [6], onde a densidade de energia é descrita de forma bilinear em termos do campo elétrico. Consequentemente a solução gera uma distribuição semi-positiva definida e não linear devolvendo assim uma característica qualitativa presente nos procedimentos de covariância de turbilhões.

Foram determinadas uma série de distribuições espaciais e temporais-espaciais e comparadas com distribuições com o coeficiente de difusão real obtidas nas mesmas condições. Devido ao fato que por enquanto não existir uma prescrição de como determinar os parâmetros do modelo de forma à representar o fenômeno físico então geram-se soluções para uma variedade de partes imaginárias dos coeficientes de difusão. Assim avalia-se o comportamento da solução ao variar a parte imaginária do coeficiente
\end{abstract}


de difusão onde observa-se um alargamento da distribuição juntamente com oscilações o que concorda com o aumento do coeficiente, que no caso real quanto maior coeficiente de difusão mais rápido ocorre a dispersão. Outro aspecto encontrado foram distribuições que abrem a possibilidade de descrever o fenômeno de meandro, que em condições de vento fraco e próximo a fonte a dispersão de poluentes é irregular e indefinida onde a pluma está sujeita a ondulações horizontais à direção do vento, a partir de uma equação tipo advecção-difusão.

Comparou-se o modelo de dispersão de poluentes com coeficiente de difusão real e complexo para a mesma situação podendo observar qualitativamente a inclusão da fase no modelo. O modelo de dispersão de poluentes presente abre a possibilidade de descrever propriedades filigranas do fenômeno ao custo de poucos parâmetros. Descrições comparáveis com um modelo puramente real precisaria de um conjunto exorbitante de parâmetros para obter o mesmo efeito.

Todos os resultados ainda são preliminares para garantir que esta será uma modificação justificada a partir de primeiros princípios, mas pretende-se estudar e incluir uma dependência temporal e espacial mais adequada no coeficiente de difusão e até mesmo substituir o coeficiente de difusão real por um complexo nas demais direções e subsequentemente validar os resultados com resultados experimentais.

\section{Referências}

[1] R. B. Stull, An Introduction to Boundary Layer Meteorology, Kluwer Academic Publishers, (1988), Dordrecht, Holanda.

[2] A. Hussain e K. M. Fazle, Coherent structures and turbulence, Journal of Fluid Mechanics, pag. 303, v. 173, (1986).

[3] S. K. Robinson, The kinematics of turbulent boundary layer structure, Tech. Memo. 103859, (1991), NASA.

[4] S. P. Arya, Air Pollution Meteorology and Dispersion, Oxford University Press, New York, USA, (1999).

[5] B. E. J. Bodmann and J. R. S. Zabadal and M T Vilhena and R Quadros, On Coherent Structures from a Diffusion-Like Model, Springer New York Heidelberg Dordrecht London, 1-10, 2013.

[6] J. D. Jackson, Classical electrodynamics, Wiley, 3 ed., New York, NY, (1999). 